\begin{tabular}{|c|c|c|}
\hline 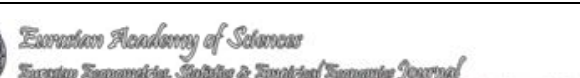 & $\begin{array}{r}\text { Eurasian Academy of } \\
\text { Eurasian Econometrics, Statistics \& Em }\end{array}$ & nics Journal \\
\hline 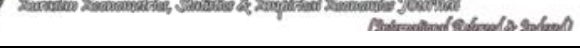 & $2015 \quad$ Volume:1 & S: $43-56$ \\
\hline \multicolumn{3}{|c|}{$\begin{array}{l}\text { Published Online April } 2015 \text { (http://econstat.eurasianacademy.org) } \\
\text { http://dx.doi.org/10.17740/eas.stat.2015-V1-04 }\end{array}$} \\
\hline
\end{tabular}

\title{
Effectiveness of technical analysis indicators over stock return: A Panel Data Approach
}

\section{Kutluk Kagan Sumer*}

* Department of Econometrics, Faculty of Economics, Istanbul University, Istanbul, Turkey E-mail:kutluk@istanbul.edu.tr

Copyright (C) 2015 Kutluk Kagan Sumer. This is an open access article distributed under the Eurasian Academy of Sciences License, which permits unrestricted use, distribution, and reproduction in any medium, provided the original work is properly cited.

\begin{abstract}
Technical analysis aims on visually identifying geometrical patterns and indicators in price charts in order to anticipate price "trends". This paper investigates the relations between return and technical analysis indicators of Turkish commercial banking sector in BISTBANKING index for the period 1-1-2000- 31-12-2013. Technical analysis indicators are generated by taking into account the daily stock prices. The general steps go through the identification of the relations for the securities returns and technical analysis indicators. We illustrate the proposed with a panel data methodology including several securities of banking sector. Our investigation shows that there is a statistically significant relation between technical analysis indicators and stock returns as panel.
\end{abstract}

Keywords: Stock Exchange; BIST; Technical Analysis; Technical Analysis Indicators, Panel Data, Banking Sector, econometrics, econometric models, financial econometrics

JEL codes: C23;C55; C58, G17; G14

\section{Hisse Senedi Getirisi Üzerinde Teknik Analiz Göstergelerinin Etkinliği: Bir Panel Veri Yaklaşımı}

Özet: Teknik analiz temel olarak fiyat grafikleri üzerindeki geometrik şekiller ve göstergeler yardımıyla fiyat trendlerini tanımlamayı amaçlar. Bu çalışma hisse senedi getirileriyle teknik analiz göstergeleri arasındaki ilişkiyi 1-1-2000 ile 31-12-2013 tarihleri arasında BISTBankacılık endeksindeki Türk ticari bankaları üzerinde araştırmayı amaçlamaktadır. Teknik analiz göstergeleri günlük hisse senedi fiyat verilerinden temin edilmiştir. Burada ana adım hisse senedi getirileriyle teknik analiz göstergeleri arasındaki ilişkiyi ortaya koymaktır. $\mathrm{Bu}$ amaçla bankacılık sektöründeki çeşitli bankaların hisse senetlerini kapsayan panel veri metodolojisi kullanılmıştır. Sonuç olarak panel olarak teknik analiz göstergeleriyle hisse senedi getirileri arasında istatistiki anlamlı bir ilişki bulunmuştur.

Anahtar Kelimeler: Borsa, BIST, Teknik Analiz, Teknik Analiz göstergeleri, Panel Veri, Bankacılık Sektörü, Ekonometri, Ekonometrik Model, Finansal Ekonometri 


\section{GíRiş}

Etkin piyasalar hipotezi bir piyasada, piyasaya gelen yeni bir bilginin tüm yatırımcılara aynı anda ulaştığı varsayılmakta ve piyasada pozisyon alan yatırımcıların normalin üzerinde kazanç elde edemeyeceği belirtilmektedir. Yine etkin piyasalar hipotezine göre etkin bir piyasada sistematik anomaliler ortaya çıkmamakta ve menkul kıymete ait fiyatlar piyasada tamamen rastlantısal bir şekilde oluşmaktadır (Fama,1970).

$\mathrm{Bu}$ durumda teknik analiz gibi teknikler fiyat hareketlerini belirleyememelidir. Oysa uygulamada gerek kısa zamanlı verilerde gerekse yüksek frekanslı verilerde neredeyse en s1k kullanılan yöntem teknik analiz ola gelmektedir. Kimi çalışmalar teknik analiz formasyonlarını bilimsellikten uzak bir fal olarak dahi değerlendirmektedir. Bununla birlikte davranışsal finansçılar ise teknik analizi aynı trendleri gören yatırımıcıların, aynı ortak hareketleri sergileyerek bekledikleri trendleri oluşturması olarak değerlendirmektedir. Her ne kadar teknik analiz formasyonları ampirik olarak modellenemeyecek olsa da teknik analiz yardımıyla elde edilen teknik indikatörler (Bolinder Bantları, MACD, ROC, CCI, MA20, Momentum, RSI gibi) gerek fiyatların gerekse getirilerin tahmininde birer zaman serisi olarak kullanılabilirler.

$\mathrm{Bu}$ çalışma panel veri metodolojisiyle bankacılık sektöründeki firmaların getirileriyle bu teknik analiz indikatörlerinin ilişkisini incelemeye yöneliktir. Daha önce de belirtildiği gibi bu indikatörlerle getiriler arasında bir ilişkinin varlığı açıç̧a etkin piyasalar hipotezinin zayıf formda etkinlik varsayımını ortaya koyacaktır.

\section{Kullanılan Veriler:}

Modelde Borsa İstanbul bankalar endeksi (XBANK) da yer alan bankalara ait hisse senelerinin getirileri ve teknik analiz indikatörleri kullanılmıştır.

Tablo-1 de yer alan bankaların 1 Ocak 2000 - 31 Aralık 2013 arasındaki günlük değerleri kullanılmıştır. Sonuç itibariyle her değişken zamanın sütun bankanın ise satır olduğu bir panel değişkendir.

Bağımlı panel değişkenimiz sırasıyla bankalara ait hisse senetlerimizin getirilerine ait bir panel değişkendir. Bağımsız değişken olarak kullanılan değişkenler ise MA20 PSAR CCI PD_DD MACD TRIGGER RSI WLR H_L FBOLU FBOLA RETURN_L1 teknik indikatörleridir. Bağımsız değișkenlerin tamamı modelde bir gecikmeli kullanılmıștır. Yani model bir gün sonrasının getirilerini tahmin etmeye yöneliktir. Süreçte zamandan ve kesitte bankalardan oluşan bu bağımsız panel değişkenlerin açıklamaları aşağıda verilmiştir. 
Tablo-1: Borsa İstanbul Bankalar Endeksi (XBANK) da Yer Alan Bankalar

\begin{tabular}{|l|l|l|}
\hline & Kod & Şirket Adı \\
\hline 1 & AKBNK & AKBANK \\
\hline 2 & ALBRK & ALBARAKA TÜRK \\
\hline 3 & ALNTF & ALTERNATIFBANK \\
\hline 4 & ASYAB & ASYA KATILIM BANKASI \\
\hline 5 & DENIZ & DENIZBANK \\
\hline 6 & FINBN & FINANSBANK \\
\hline 7 & GARAN & GARANTI BANKASI \\
\hline 8 & HALKB & T. HALK BANKASI \\
\hline 9 & ISCTR & İS BANKASI \\
\hline 10 & KLNMA & T. KALKINMA BANK. \\
\hline 11 & SKBNK & ŞEKERBANK \\
\hline 12 & TEBNK & T.EKONOMİ BANK. \\
\hline 13 & TEKST & TEKSTILBANK \\
\hline 14 & TSKB & T.S.K.B. \\
\hline 15 & VAKBN & VAKIFLAR BANKASI \\
\hline 16 & YKBNK & YAPI VE KREDİ BANK. \\
\hline
\end{tabular}

MA20: 20 Günlük Hareketli ortalamalardır.

PD_DD: Piyasa Değeri / Defterdeğeri değerleridir.

PSAR: PARABOLIC SAR: Kısa ve orta vadede oluşan yön değişimlerinin tespitinde kullanılır. SAR sözcüğü, İngilizcedeki "Stop And Reversal" (Dur ve Geri dön) sözcüklerinin baş harfleridir. Formülü aşağıdaki gibidir:

$\mathrm{SARn}+1=\mathrm{SARn}+\alpha($ EP-SARn $)$

$\mathrm{Bu}$ formülde yer alan SARn değeri şu anda görülen fiyatı, SARn +1 değeri ise bir sonraki gün görülen fiyatı temsil eder. EP Uç Nokta (extreme point) değeri, isminden de anlaşılabileceği gibi trendlerin dip veya zirve seviyesini temsil etmektedir. Parabolic SAR indikatörünün hesaplandığı trend yükselen trend ise zirve, düşüş trendi ise dip noktası seçilir. $\alpha$ değeri, akserelasyon yani hızlanma faktörü olarak isimlendirilir. Wilders, yapmıș olduğu istatistik çalışmaları sonrası bu değeri 0.02 olarak belirlemiştir. SAR noktaları fiyatların üzerinden fiyatların altına düşerse al, fiyatların altındayken fiyatların üstüne geçerse de sat sinyali olarak yorumlanır. 


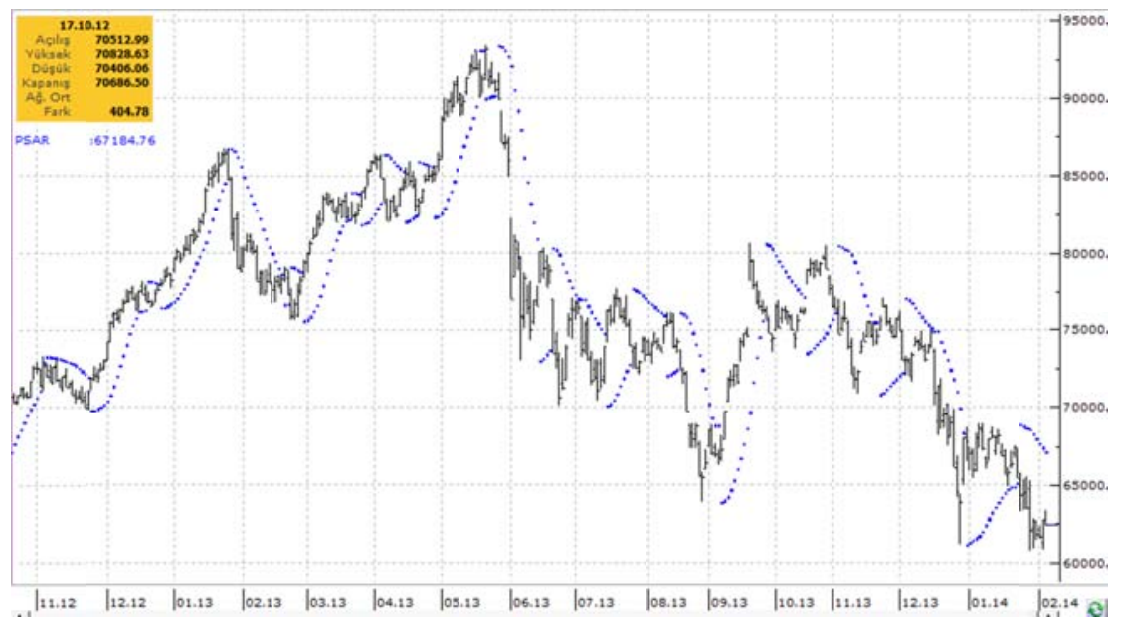

CCI: COMMODITY CHANNEL INDEX : Bu gösterge aşırı alım(overbought) ve aşırı satım(oversold) bölgelerini gösteren bir osilatördür. CCI osilatöründe +100 seviyesinin üzeri aşırı alım,-100 seviyesinin altı ise aşırı satım bölgesidir. Bu seviyelerden fiyatın tekrar aksi yönde hareket etmesi ise trend değişikliği şeklinde yorumlanır. Bu seviyelerden fiyatın tekrar aksi yönde hareket etmesi ise trend değişikliği şeklinde yorumlanır. Bu osilatör, emtia piyasaları için geliştirildiği için on bir günlük periyota alternatif olarak $\mathbb{1 4}$ günlük periyotta yaygın olarak kullanılmaktadır.

CCI indikatörü hesaplanırken, öncelikle gün içi en yüksek, en düşük ve kapanış fiyatının üçe bölünmesiyle elde edilen orta fiyat bulunur. Daha sonra seçilen gün sayısına ait orta fiyat hesaplanır. Bir sonraki aşamada, hesaplanan orta fiyatların basit hareketli ortalaması alınır. Daha sonra seçilen gün sayısının orta fiyatları toplamından, hesaplanan orta fiyatların basit hareketli ortalaması birer birer çıkarılır. Çıkan sonucun mutlak değeri alınır ve mutlak değeri alınan farklar, seçilen gün sayısına bölünerek ortalama sapma bulunur. Daha sonra, ortalama sapma 0,015 katsayısı ile çarpılır. Son aşamada ise seçilen gün sayısı için hesaplanan orta fiyatların basit hareketli ortalaması, orta fiyattan çıkarılır. Elde edilen değer ise ortalama sapmanın 0,015 katsayısı ile çarpımından elde edilen değere bölünerek CCI elde edilir.

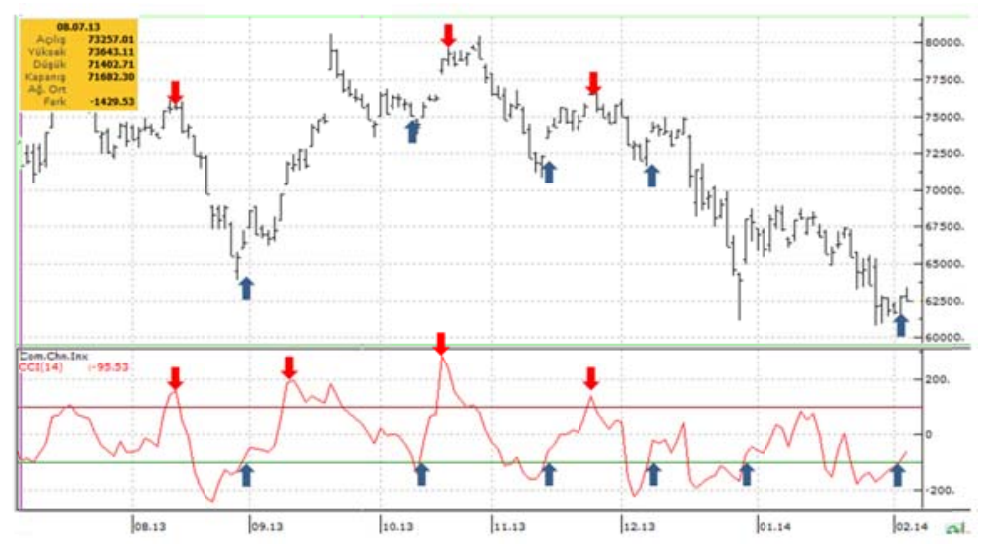

MACD VE TRIGGER: MACD (Moving Average Convergence/Divergence): Hareketli ortalamalardan türetilmiş bir indikatördür. İki hareketli ortalama arasındaki uyum veya uyumsuzluğun tespit edilmesinde kullanılır. MACD, hem trend takip edici, hem de osilatör 
olarak kullanılabilen, güvenilir bir indikatördür. Kısa vadeli hareketli ortalamadan daha uzun vadeli ortalamanın çıkartılması ve farkın üssel hareketli ortalamasının alınmasıyla hesaplanır. Göstergenin yaratıcısı Gerard Appel'e göre 12 günlük üssel hareketli ortalamadan, 26 günlük üssel hareketli ortalamanın çıkarılması ile elde edilir. Daha sonra, dönüş hareketleri ve uyumsuzluğun tespitinde yararlanılan sinyal eğrisi, MACD değerinin 9 günlük üssel hareketli ortalaması alınarak hesaplanır. Formüle dökersek:

$\mathrm{MACD}=\mathrm{EMA}(12)-\operatorname{EMA}(26)$

Sinyal $=$ EMA $(\mathrm{MACD}, 9)$

MACD indikatörünün yorumlanışında üç yaklaşım ön plana çıkmaktadır. Birinci yaklaşım, crossovers yani kesişme noktaları olarak adlandırılan seçenektir. MACD çizgisinin sinyal çizgisinin altına sarkması sat, üstüne çıkması ise al sinyali olarak yorumlanır. Buna ek olarak 0 seviyesinin, denge noktası kabul edilmesi nedeniyle, bu seviyenin altına sarkması sat, üstüne çıkılması ise al sinyali olarak kabul edilir.

İkinci yaklaşım ise aşırı alım ve aşırı satım durumunun tespit edilmesidir. MACD eğrisinin, sinyal eğrisinden yukarı yönde, hızlı biçimde uzaklaşması aşırı bir yükselişin olduğu ve sert bir düzeltmenin gerçekleşmesi olasılığının yükseldiği şeklinde yorumlanır. Tersi bir durumda, yani MACD eğrisinin, sinyal eğrisinden aşağı yönde, hızlı biçimde uzaklaşması ise aşırı bir düşüşün olduğu ve sert tepki yükselişlerinin gerçekleşmesi olasılığının arttığı şeklinde yorumlanır. Üçüncü yaklaşım ise uyumsuzlukların tespit edilmesidir. Fiyat hareketiyle, MACD eğrisinin aynı yönde hareket etmemesi durumu, var olan trendin artık sonuna gelinmekte olduğu şeklinde yorumlanabilir. Crossovers yani kesişme noktaları stratejisinde, dikkat edilmesi gereken nokta tepe ve dip dönüş formasyonlarıdır.

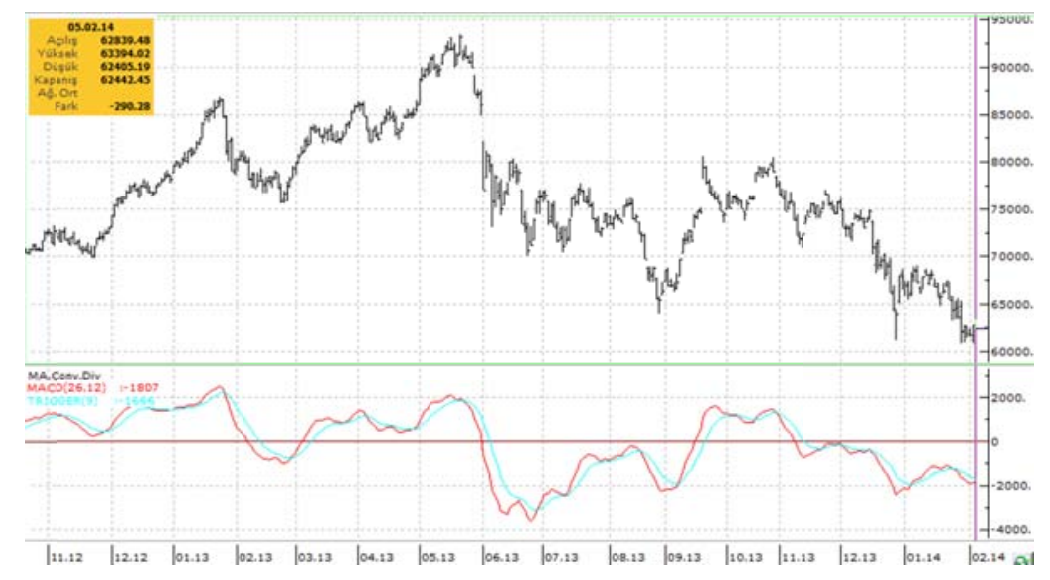

RSI : RELATIVE STRENGTH INDEX : RSI indikatörü, paritenin incelenen periyot içerisindeki kapanış değerlerinin, bir önceki güne göre değişiminden hareketle hesaplanan bir göstergedir. Hesaplanması için hesaplanan periyottaki gün sayısından bir fazla sayıda kapanış değeri elde edilir. Daha sonra seçilen gün sayısına bir eklenerek bulunan zaman diliminde, bir önceki güne göre yükselen kapanış verilerinin aritmetik ortalaması alınarak, ortalama yukarı hareket değeri bulunur. Bu aşamadan sonra, seçilen gün sayısına bir eklenerek bulunan zaman diliminde, bir önceki güne göre düşen kapanış verilerinin aritmetik ortalaması alınarak ortalama alçalan hareket değeri elde edilir. Ortalama yükselen hareketin, ortalama alçalan 
harekete bölümünden, RSI indikatörünün çekirdeği denebilecek göreceli güç (RS) değeri elde edilir. Son olarak endeks formülüne RS değeri yazılarak RSI elde edilir. Bütün bu aşamaları formülle ifade etmek gerekirse:

$\mathrm{RS}=$ Ortalama yükselen hareket / Ortalama alçalan hareket

$\mathrm{RSI}=100-(100 / 1+\mathrm{RS})$

RSI indikatörü yaygın olarak iki biçimde kullanılır. Bunlardan ilki ve en yaygını 30 seviyesi ve altının aşırı satım, 70 seviyesi ve üzerinin aşırı alım bölgesi olarak değerlendirilmesidir. $\mathrm{Bu}$ yaklaşıma göre,30 seviyesinden aşağ 1 düşen RSI eğrisinin yeniden bu seviyenin üstüne çıkması al sinyali,70 seviyesinin üstüne çıkan RSI eğrisinin yeniden bu seviyeden aşağı inmesi ise sat sinyali olarak yorumlanır. Diğer yaklaşım ise fiyat ile RSI indikatörünün arasındaki uyumsuzluktan yararlanmaktır. Genellikle RSI indikatörü, fiyat grafiği ile birlikte hareket etmektedir. Ancak zaman zaman fiyat grafiğinde görülen trendin aksi yönünde hareket edebilir.

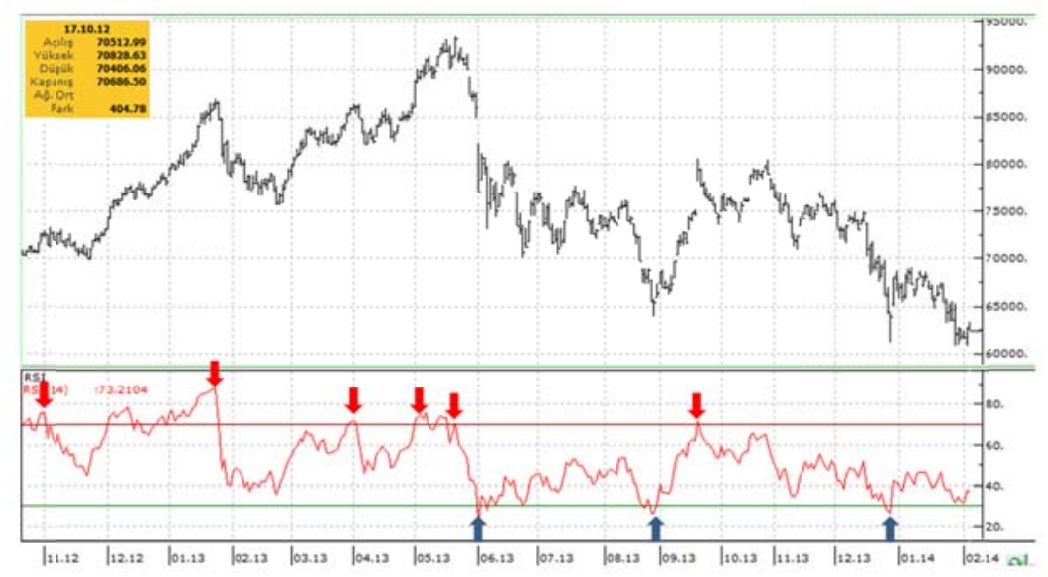

WLR: WILLIAMS \%R: Bu gösterge periyodun içinde yer alan kapanışları periyottaki en yüksek ve en düşük değere olan yakınlıklarına göre değerlendiren bir osilatördür; -100 ile 0 arasında değerler alır. Williams\%R nin kullandığı referans değerleri -20 ve -80 dir. Diğer referans değeri kullanan göstergelerde olduğu gibi burada da bu değerlerin alt ve üst kısımları aşırı alım ve aşırı satım bölgeleri olarak adlandırılır. Bir senedin fiyatının -80 referans değerinin altına inmesi aşırı satıma ve bir süre sonra toparlanma olacağına, -20 referans değerinin üzerine çıması ise aşırı alıma ve bir süre sonra gevşeme olacağına işaret eder.

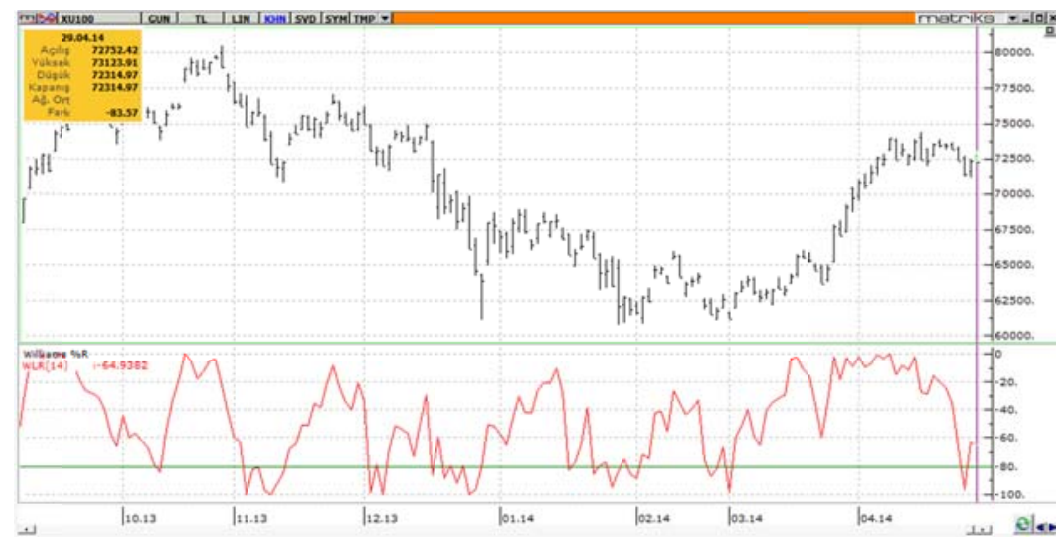


FBOLU VE FBOLA: BOLLINGER BANTLARI: Hareketli ortalamaların yukarı ve aşağı yönde standart sapma değeri kadar kaydırılması ile elde edilen göstergedir. Zaten oldukça güvenilir olan hareketli ortalamaların, standart sapma ile olası hatalarının daha da azaltılması sonucu özellikle kısa vadeli dönüşlerin yakalanmasında yüksek isabet sağlanmaktadır. Standart bir bollinger bandı analizinde orta bollinger eğrisi, yirmi günlük hareketli ortalamadır. Üst Bollinger bandı ise orta bollinger bandına 2 değeri eklenip 20 günlük standart sapma değerinin çarpılması ile elde edilir. Son olarak alt bollinger bandının hesaplanışında, orta bollinger bandından 2 değeri çıkartılır ve 20 günlük standart sapma değeri ile çarpılır.

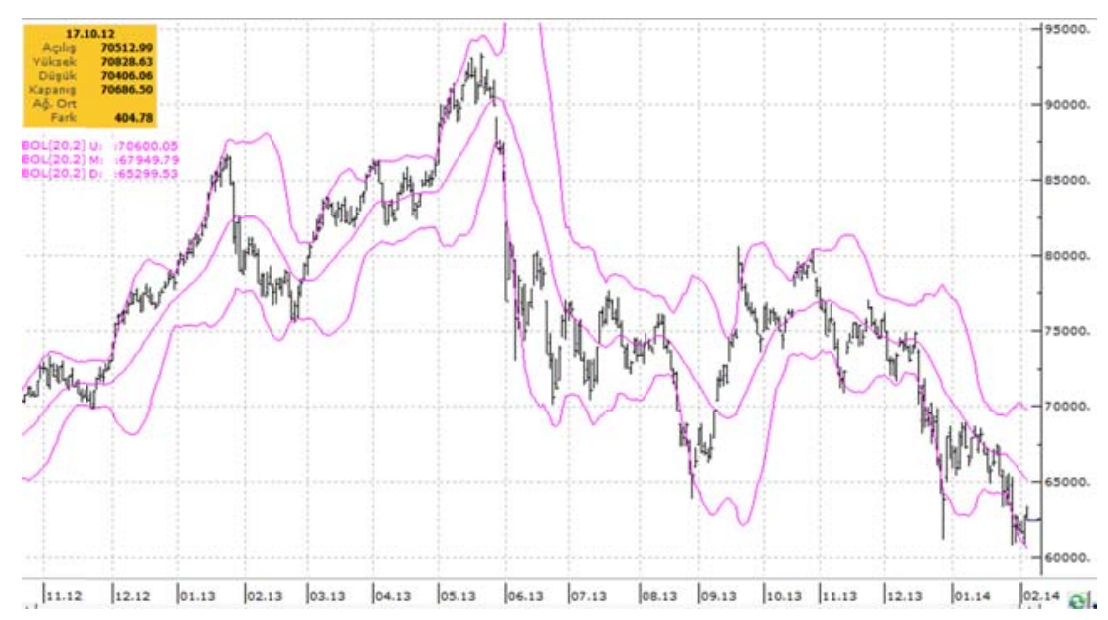

FBOLU değişkeni üst bollinger bandıyla cari fiyat arasındaki farkı FBOLA ise alt bollinger bandıyla cari fiyat arasındaki farkı iade eden değişkenlerdir. Bu fark alma işlemi standart sapmalardan ne kadar uzaklaşıldığını yansıtmaktadır.

H_L : Gün içindeki en yüksek değerle en düşük değer arasındaki farkı göstermektedir.

RETURN_L1: Bir dönem gecikmeli getiriyi ifade etmektedir.

\section{YÖNTEM:}

Çalışmada yöntem olarak panel veri regresyonu yöntemi kullanılmıştır. Yatay kesit veri birçok birim için sadece bir dönem hakkında bilgi verir. Zaman serisi verisi ise bunun aksine tek bir birim için zaman değişimini göstermektedir. Panel veri (N) sayıda birim ve her bir birime karşılık gelen (T) sayıda gözlemden oluşmaktadır. Her bir birime karşılık bir zaman serisi vardır. Zaman boyutuna sahip yatay kesit serilerinin kullanılarak ekonomik ilişkilerin tahmin edilmesi yöntemine panel veri analizi ismi verilmektedir.

$$
\begin{gathered}
Y_{\text {it }}=\beta_{1 i t}+\beta_{2 \text { it }} X_{2 \text { it }}+\ldots \ldots . .+\beta_{\text {kit }} X_{\text {kit }}+e_{\text {it }} \\
\mathrm{i}=1, \ldots \ldots, N \quad \mathrm{t}=1, \ldots \ldots, \mathrm{T}
\end{gathered}
$$

Burada $\mathrm{N}$ birimleri, $\mathrm{t}$ ise zamanı göstermektedir. Y değişkeni, birimden birime ve bir zaman periyodundan ardışık zaman periyoduna farklı değerler alan bağımlı bir değişken olduğunda, 
kesit boyutu için i, zaman periyodu için $\mathrm{t}$ olmak üzere iki alt indisle ifade edilmektedir. $\mathrm{Bu}$ genel model, sabit ve regresyon parametrelerinin her zaman periyodunda her bir birey için ayrilmasina izin vermektedir.

Panel veri sadece yatay kesit ya da sadece zaman serisi ile karşılaştırıldığında çeşitli avantajlara sahip bulunmaktadır. Panel veri kullanmanın avantajları şunlardır. Panel veri modellerinde gözlem sayısı kesit ve zaman serilerine göre daha fazla olacaktır. Bu durumda elde edilecek parametre tahminleri daha güvenilir olacak ve tahmin edilen modeller daha az kısitlayıc1 varsayıma dayanacaktır. Oysa sadece zaman serisi veya kesit verisi ile yapılan çalışmalarda, sapmalı sonuçlar elde etme riski söz konusu olacağından birimlerin farklıkları ayrıntılı olarak kontrol edilemez. Ayrıca panel veri modelleri tamamıla kesit ya da zaman serilerinden daha karmaşık davranış modellerinin kurulmasına ve test edilmesine olanak tanır. Bununla birlikte dişlanan değişkenler, zaman serisi veya yatay kesit verisi kullanılarak yapılan çalışmalarda tahmin sonuçlarında sapmaya yol açarken; dışlanan değişken veya değişkenlerin birimlere veya zamana göre değişmeyen değişkenler olması durumunda, panel veri kullanımı sapmanın kontrol altına alınmasını sağlamaktadır. Panel veri kullanmanın diğer bir avantajı da; yatay kesit verisi kullanılarak yapılan tahminlerde, sadece birimler arasındaki farklıklar incelenebilirken, panel veri kullanılarak hem birimler hem de bir birim içerisinde zaman içerisinde meydana gelen farkl1lıklar birlikte incelenebilmektedir. (Baltagi, 1995;3-5, Hsiao,1986;2-3)

Denklem (1) ile ifade edilen modelde, katsayılar farklı birimler için farklı zaman periyotlarında farklı değerler almaktadır. $\mathrm{Bu}$ durumda tahmin edilen parametre sayısı, kullanılan gözlem sayısını aşmakta, yani model tahmin edilememektedir. Bu dezavantaj yüzünden panel veri ile yapılan çalışmalarda daha çok hata terimlerinin özellikleri ve katsayıların değișebilirliği ile ilgili farklı varsayımlarda bulunarak farklı modeller elde edilebilmektedir. Farklı varsayımlarla elde edilen modeller "Sabit Etkili" ve "Tesadüfi Etkili" modellerdir. Her iki modelde de, eit hatalarının tüm zaman dönemlerinde ve tüm bireyler için bağımsız ve N $\left(0, \quad e^{2}\right)$ şeklinde dağıldığı varsayılmaktadır. (Griffits, 1993; 571-573)

\section{$\underline{\text { Sabit Etkili Modeller }}$}

Panel veri kullanılarak yapılan çalışmalarda birimler arasındaki farklılıklardan veya birimler arasında ve zaman içinde meydana gelen farklıklardan kaynaklanan değişmeyi, modele dahil etmenin bir yolu; mevcut değişmenin regresyon modelinin katsayılarının bazılarında veya tümünde değişmeye yol açtığını varsaymaktadır. Katsayıların birimlere veya birimler ile zamana göre değiştiğinin varsayıldığı modellere "Sabit Etkili Modeller" denmektedir.

Modelin genel formülasyonu, birimler arasındaki farklılıkların sabit terimdeki farklılıklarda yakalanabildiğini varsaymaktadır. (Pazarlıoğlu, 2001) Bu amaçla panel veri modeli kukla değişken yardımıyla tahmin edilmektedir. 1'nolu model ele alındığında,

$$
\beta_{1 \text { it }}=\beta_{1} ; \beta_{2 \text { it }}=\beta_{2} ; \beta_{3 i t}=\beta_{3}
$$

olduğu varsayılmaktadır. Burada yalnızca sabit parametre değişmekte ve sabit terim zamana göre değil ama kesit bazında farklılıklar göstermektedir. Yani zaman boyutu sabit tarafından muhafaza edilmesine rağmen bireyler arasındaki davranışlarında farklıllık gösterdiği ifade edilmektedir. 1'no'lu model,

$$
\mathrm{Y}_{\mathrm{it}}=\beta_{1 \mathrm{i}}+\beta_{2 \mathrm{i}} \mathrm{X}_{2 \mathrm{it}}+\ldots \ldots . .+\beta_{\mathrm{ki}} \mathrm{X}_{\mathrm{kit}}+\mathrm{e}_{\mathrm{it}}
$$


haline gelir. Bu modeli $\beta_{\text {lit }}$ ifadesi açılarak yeniden yazılırsa,

$$
\begin{gathered}
Y_{i t}=\beta_{11} D_{1 i}+\beta_{12} D_{2 i}+\ldots \ldots+\beta_{1 N} D_{N i}+\beta_{2 i} X_{2 i t}+\beta_{k i} X_{k i t}+e_{i t} \\
\sum^{N} \beta_{1 j} D_{j i}+\sum^{K} \beta_{k} X_{k t}+e_{i t}
\end{gathered}
$$

elde edilir. Burada N birey ve K-1 tane açıklayıcı değişken vardır. Ayrıca;

$$
D_{1 i}=\left\{\begin{array}{lr}
1, & i=1 \\
0, & \text { Diğ } \text { er Durumlar }
\end{array} \quad, D_{1 N}=\left\{\begin{array}{lr}
1, & i=N \\
0, & \text { Diğer Durumlar }
\end{array}\right.\right.
$$

$\mathrm{Bu}$ modelde, sabit katsayı yer almadığından $\mathrm{N}$ sayıda birim arasındaki farklılık N sayıda kukla değişken kullanılarak incelenmektedir.

\section{$\underline{\text { Tesadüfi Etkili Modeller }}$}

Panel veri ile yapılan çalışmalarda, birimlere veya birimlere ve zamana göre meydana gelen farklılıklardan kaynaklanan değişim "Sabit Etkili Modeller" kullanılarak incelenebileceği gibi, "Tesadüfi Etkili Modeller" kullanılarak da incelenebilmektedir. Tesadüfi etkili modellerde, birimlere veya birimlere ve zamana göre meydana gelen değişiklikler, modele hata teriminin bir bileşeni olarak dahil edilmektedir. Bunun temel sebebi sabit etkili modellerde karşılaşılan serbestlik derecesi kaybının önlenmek istenmiş olmasıdır (Baltagi, 1995; 13). Çünkü tesadüfi etkiler modelinde önemli olan birime veya birime ve zaman özel katsayıların bulunması değil, birime veya birime ve zamana özel hata bileșenlerinin bulunmasıdır. Ayrıca tesadüfi etkiler modelinde, sadece gözlenen örnekteki kesit, birimler ve zamana göre meyanda gelen farklılıkların etkisini değil, örnek dışındaki etkileri de dikkate almaktadır. (Greene,2003). Tesadüfi etkiler modelini şu şekilde açıklayabiliriz. (3) nolu modelde $\bar{\beta}_{1}$ i tesadüfi değişken olarak alınıp,

$$
\beta_{1 \mathrm{i}}=\bar{\beta}_{1}+\mu_{\mathrm{i}}
$$

şeklinde modellenmektedir. $\bar{\beta}_{1}$ anakütle ortalama sabiti olup bilinmeyen parametredir ve $\mu_{\mathrm{i}}$, birey davranışlarındaki bireysel farklılıkları dikkate alan gözlenemeyen tesadüfi hatalardır. $\mu_{\mathrm{i}}$ 'ler birbirlerinden ve e it'lerden bağımsızdır. (5) nolu eşitlik (3) nolu modelde yerine konulursa;

$$
\begin{aligned}
& \mathrm{Y}_{\mathrm{it}}=\left(\bar{\beta}_{1}+\mu_{\mathrm{i}}\right)+\beta_{2} \mathrm{X}_{2 \mathrm{it}}+\ldots . .+\beta_{\mathrm{k}} \mathrm{X}_{\mathrm{kit}}+\mathrm{e}_{\mathrm{it}} \\
& =\bar{\beta}_{1}+\sum_{k=2}^{K} \beta_{k} X_{k i t}+\left(e_{i t}+\mu_{i}\right)
\end{aligned}
$$

elde edilir. (6b)' deki ifade hata bileşen modelinin genel biçimidir. "hata bileșen" ifadesi $\mathrm{e}_{\mathrm{it}}+\mu_{\mathrm{i}}$ teriminden kaynaklanmaktadır. Bu terim iki bileşenden meydana gelmektedir: $\mathrm{e}_{\text {it }}$ tüm hataları gösterirken, $\mu_{i}$, bireysel "spesifik" hata, bireysel farklılıkları ve sabit zamana göre bireyler arasındaki değişmeyi gösterir. 


\section{$\underline{\text { Hausman Testi }}$}

Birim veya birim ve zaman farklılıklarını temsil eden katsayıların yani tesadüfi etkili modelin hata terimi bileşenlerinin modeldeki bağımsız değişskenlerden ilişkisiz olduğu hipotezinin geçerliliği, Hausman tarafindan önerilen test istatistiği ile incelenebilmektedir (Greene, 2003). $\mathrm{Bu}$ durumda sabit etki model parametre tahmincileri ile tesadüfi etkili modelin parametre tahmincileri arasındaki farkın istatistiksel olarak anlamlı olup olmadığının incelenmesi gerekmektedir. İki model arasında tercih yapabilmek için Hausman test istatistiği kullanılmaktadır. Hausman test istatistiği "Tesadüfi etkiler tahmincisi doğrudur." sıfır hipotezi altında k serbestlik dereceli ki-kare dağılımı göstermektedir. Gerçekleşmesi durumunda tesadüfi etkili modelin hata terimleri bileşenlerinin bağımsız değişkenler ile ilişkili olmadığı kararı verilebilecektir. Bu durumda sabit etkili modeli tercih edilecektir.

\section{AMPÍRIKK BULGULAR:}

Daha önce üzeinde durulan veri seti yardımıyla panel veri modellemesi için matrisler tanımlanmış söz konusu zaman ve mekan matrisleri yardımıyla panel veri ekonometrisi teknikleri Stata 12 paket programı ile yapılmıştır. Modeldeki bağımlı değişken (RETURN) hisse senetlerinin getirileridir. Bağımsız değişkenler MA20, PSAR, CCI, PD_DD, MACD, TRIGGER, RSI, WLR, H_L, FBOLU,FBOLA, RETURN $\mathrm{t}_{\mathrm{t}-1}$, dir.

İlk önce daha önce sabit etkiler modeli kurulur. Bu modele ait Stata çıktısı aşağıdaki gibidir. $\mathrm{P}>|\mathrm{z}|$ sütununa bakılacak olursa bütün parametreler $\% 95$ seviyesinde anlamlıdır.

Model incelendiğinde birim etkiler olduğu ve klasik modelin uygun olmadiğı görülebilir. İkinci aşamada zaman etkisi olup olmadığı incelenecek olunursa bu modele ait Stata çıtısı aşağıdaki gibidir. $\mathrm{P}>|\mathrm{z}|$ sütununa bakılacak olursa bütün parametreler $\% 95$ seviyesinde anlamlidir.

Model incelendiğinde zaman etkisi olduğu ve klasik modelin uygun olmadığ görülebilir. Üçüncü aşamada çift yönlü etki araştırılacak olunursa bu modele ait Stata çıktısı aşağıdaki gibidir. $\mathrm{P}>|\mathrm{z}|$ sütununa bakılacak olursa

Model incelendiğinde çift yönlü etki olduğu ve klasik modelin uygun olmadığı görülebilir. Bu aşamada nihai karar olarak panel veri modelinin kullanımı doğrudur. Dördüncü aşamada Tesadüfi etkiler modeli mi, sabit etkiler modelimi kullanılacak buna karar vermemiz gerekir ki bu da daha önce bahsettiğimiz üzere Haussman testiyle karar verilecektir. 

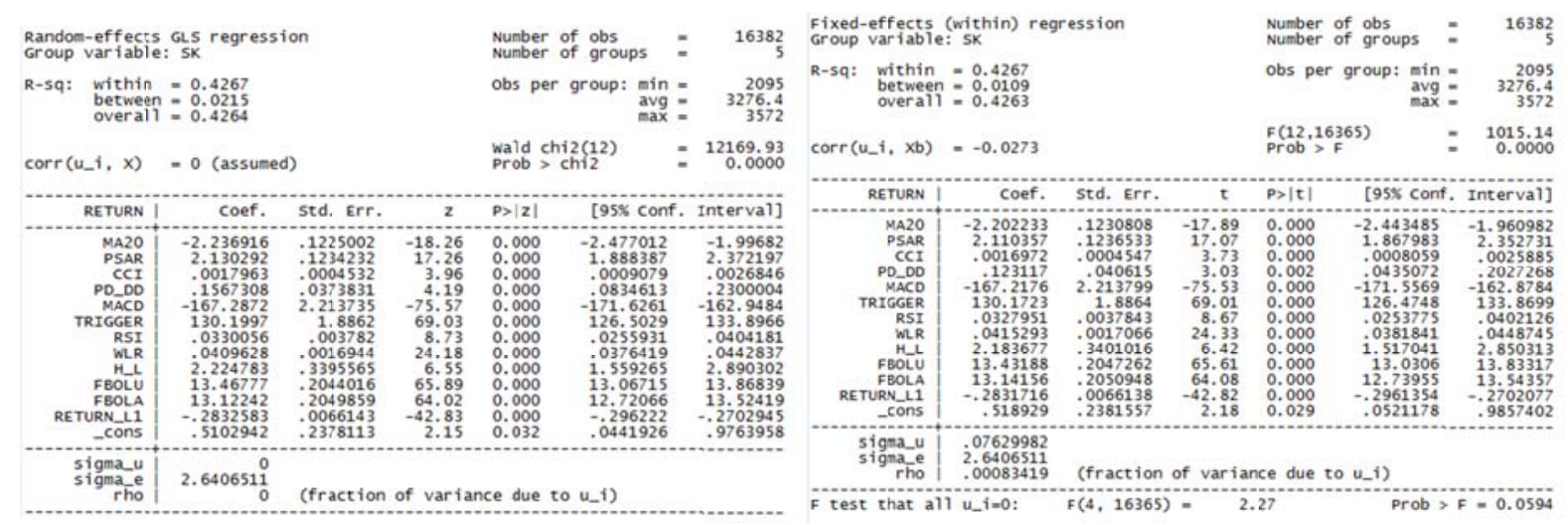

\section{$\underline{\text { Hausman Testi }}$}

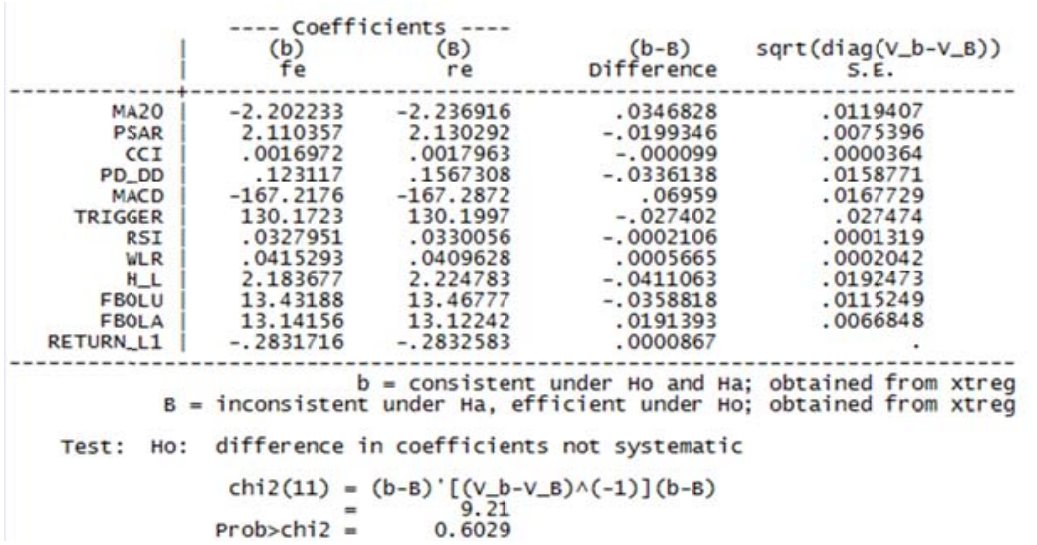

$\mathrm{H}_{0}$ Kabul Tesadüfi Etkiler modeli Tutarlı

Hausman testi incelendiğinde tesadüfi etkiler modeli kabul edilir. Bundan sonra spesifikasyon hatalarının testlerine tesadüfi etkiler modeli varsayımlarına göre devam edilir. Testlede kullanılacak model aşağıdaki gibidir. . $\mathrm{P}>|\mathrm{z}|$ sütununa bakılacak olursa bütün parametreler \%95 seviyesinde anlamlıdır. 


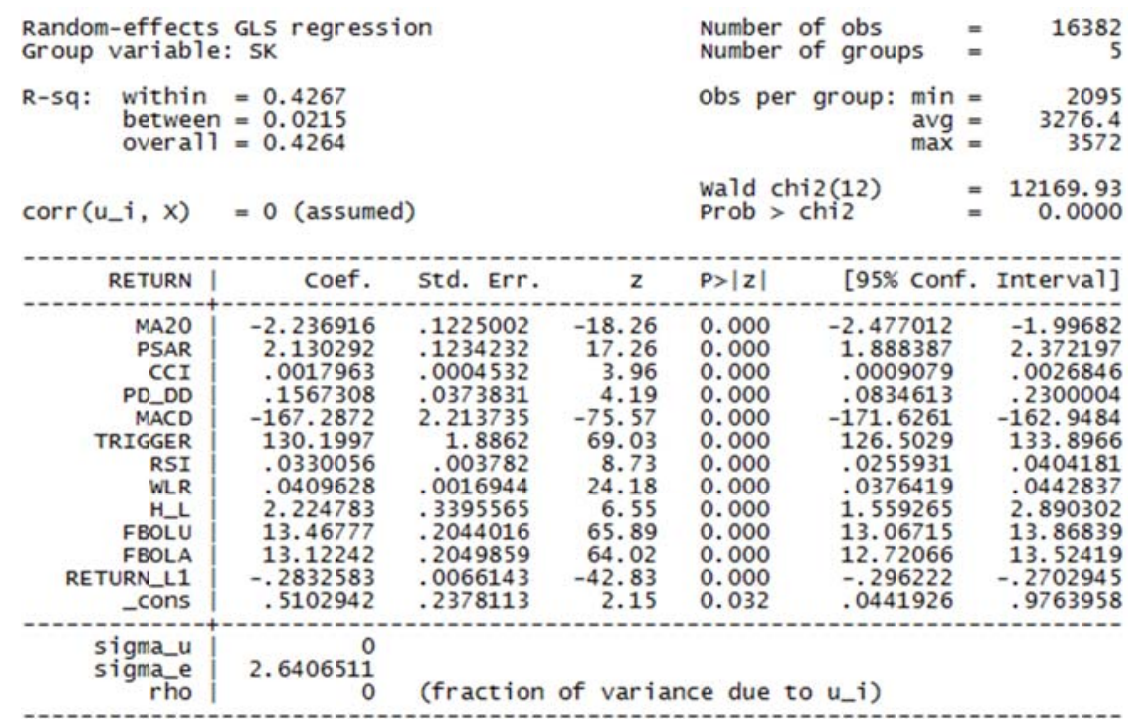

Modelde heteroskedasite yoktur.

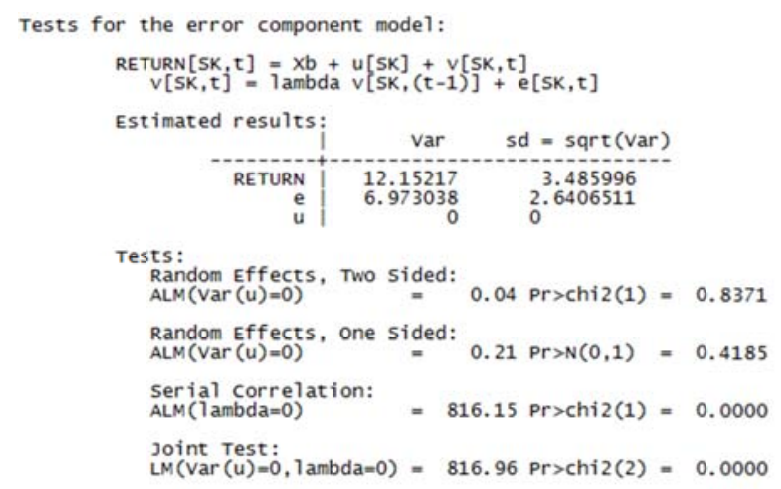

Pesaran's test of cross sectional independence $=73.327, \operatorname{Pr}=0.0000$

Birimler arasında otokorelasyon vardır.

Friedman's test of cross sectional independence $=5346.218, \operatorname{Pr}=0.0000$

$\mathrm{H}_{0}$ kabul edilmektedir birimler arasında korelasyon vardır.

Frees' test of cross sectional independence $=0.881, \operatorname{Pr}=0.0000$

Otokorelasyon ve birimler arasında otokorelasyon problemleri görüldüğüne göre robust bir tahmin yöntemine başvurulacak olunursa Robust Tesadüfi Etkiler Modeli aşağıdaki gibi olacaktır. Bu model nihai kullanılacak nihai model olacaktır. Modelde açık olarak teknik analiz indikatörlerinin bankacılık sektöründeki hisse senetlerinin getirilerini etkilediği görülmektedir. 


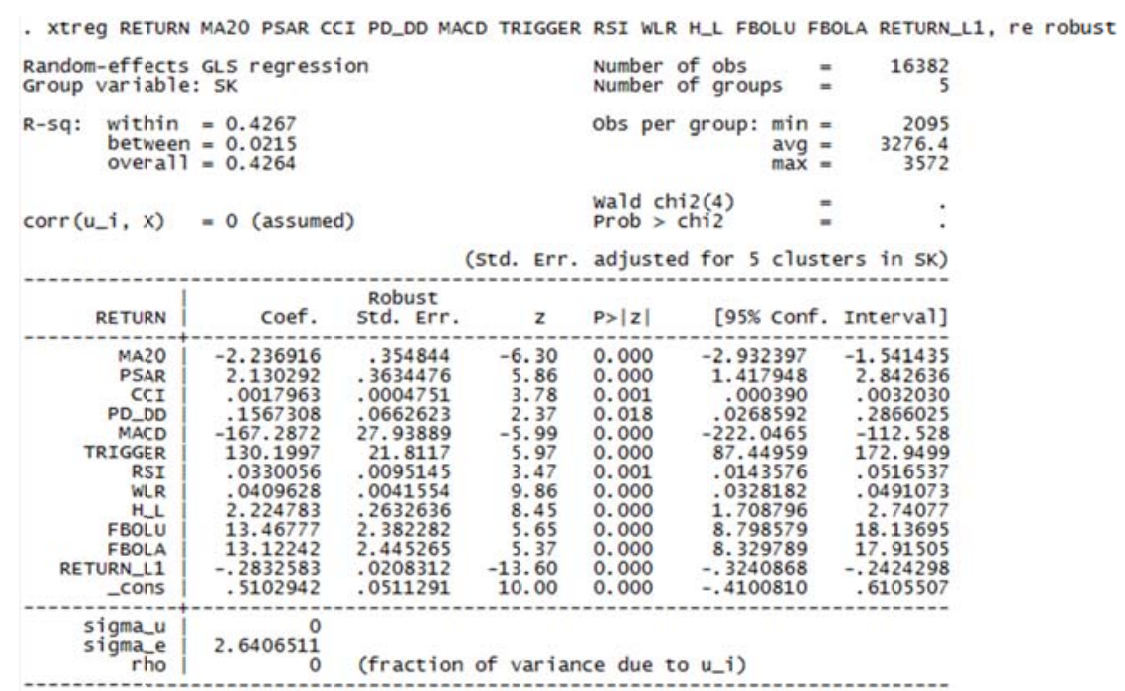

\section{SONUÇ:}

Bankacılık sektöründeki hisse senetlerinin getirileri üzerinde teknik analiz indikatörleri arasında kurulan panel veri modelinde açık olarak teknik analiz indikatörlerinin bankacılık sektöründeki hisse senetlerinin getirilerini etkilediği görülmektedir. Bütün parametreleri anlamlı olan bu model aşağıdaki gibidir.

$$
\begin{aligned}
& 0.510-2.236 \mathrm{MA} 20+2.130 \mathrm{PSAR}+0.001 \mathrm{CCI}+0.156 \mathrm{PD} \mathrm{DD} \\
& \text { RETURN }=-167.287 \text { MACD }+130.199 \text { TRIGGER }+0.033 \mathrm{RSI}+10.040 \overline{\mathrm{WLR}} \\
& +2.264 \text { H_L }+13.467 \text { FBOLU }+13.122 \text { FBOLA - 0.283 RETURN } \text { t- }_{\text {- }} \\
& 1
\end{aligned}
$$

İlk sonuç olarak beklentilerin tam tersine teknik analiz indikatörleri getiri beklentileri üzerinde etkili olduğu belirtilebilir.

İkinci önemli sonuç bir gün öncesinden beklenen getiriyi tahmin etmeye yönelik bir model elde edilmiştir.

Üçüncü önemli sonuç ise menkul kıymete ait fiyatlar piyasada tamamen rastlantısal bir şekilde oluşmaktadır temel varsayımından hareket eden etkin piyasalar hipotezinin tersine sistematik anomaliler ortaya çıkmamaktadır. Teknik analiz indikatörleri ile getiriler arasında bir ilişkinin varlığı açıkça etkin piyasalar hipotezinin zayıf formda etkinlik varsayımını Borsa İstanbul'da ve bankacılık sektöründe ortaya koymaktadır.

Tartışma: Bu çalışmanın ışığında Teknik analiz indikatörleri ile Getiriler arasında ki ilişkinin diğer borsalar, sektörler üzerinde geçerliliği bu çalışmayla ortaya çıkan yeni bir tartışma konusudur. Acaba bu ilişki tek bir sektör ve borsa için mi geçerlidir? Elde edilen parametreler stabil ve evren parametresi özelliğinde midir? Diğer sektör ve borsalar için de bir geçerliliği var midir? 


\section{REFERENCES}

- FAMA F.E. (1970). Efficient capital markets: a review of theory and empirical work. The Journal of Finance, 25(2), 383-417. SÜMER K.K. (2013) "An Early Warning Model with Technical Indicators: The Case of Ise (Istanbul Stock Exchange)," iBusiness, Vol. 5 No. 4, pp. 173-183. doi: 10.4236/ib.2013.54022.

- TARI Recep (2010) Ekonometri Umuttepe Yayınları 10. Bask1, 2010

- TATOĞLU, Ferda (2012) Yerdelen Panel Veri Ekonometrisi; Beta Basım A.Ş.; Istanbul; 2012

- GREENE, W.H. (2003), Econometric Analysis, Prentice Hall, New Jersey

- GRIFFITS, W. E. R \& CARTE H. (1993). Learning and Practicing Econometrics, John Wiley, New York,

- HSIAO C. (1986) Analysis of Panel Data, Cambridge University Press

- PAZARLiOĞLU, .M.V. (2001) 1980-1990 Döneminde Türkiye' de İç Göç Üzerine Ekonometrik Model Çalışması, V.Ulusal Ekonometri ve İstatistik Sempozyumu, 1922 Eylül 2001, Adana

- PAZARLIOĞLU V., GÜRLER; (2007) Telekomünikasyon yatırımları ve ekonomik büyüme: panel veri yaklaşımı; 8. Türkiye Ekonometri ve İstatistik Kongresi 24-25 Mayıs 2007 - İnönü Üniversitesi Malatya

- BALTAGi B.H., (1995), Econometric Analysis of Panel Data, John Wiley \& Sons Ltd, England 